\title{
HUBUNGAN PERSEPSI TENTANG KUALITAS DAN PELAYANAN PENDIDIKAN DENGAN KEPUASAN ORANG TUA SISWA SEKOLAH MENENGAH KEJURUAN NEGERI
}

\author{
Dyah Ayu Ningsih \\ Ali Imron \\ Teguh Triwiyanto
}

\author{
ayudyah337@gmail.com \\ Universitas Negeri Malang, Jl. Semarang No. 5 Malang 65145
}

\begin{abstract}
The purpose of this research is to know: the level of perception about quality of education; the level of educational services; the level of the parents' satisfaction; the correlation between perception about the quality of education and parents' satisfaction; the correlation between educational services and parents' satisfaction; the correlation between perception about the quality of education and education services; and the correlation between perception of quality and service of education with the parents' satisfaction. This research uses quantitative approach with descriptive correlational research design. The instrument used in collecting data in the form of a questionnaire with the respondents parents of students of SMK Negeri in Mojokerto City. Data analysis technique used is descriptive analysis technique (mean) and multiple regression analysis technique. Based on the results of research can be concluded that: the level of perception about the quality of education is in medium category; the level of education service is in high category; the level of parents' satisfaction is in the medium category; there is a significant correlation between the perception about quality of education and parents' satisfaction; there is a significant correlation between the education services and parents' satisfaction; there is a significant correlation between the perception about the quality of education and education services; and there is a significant correlation between the perception about the quality of education and education service with the parents' satisfaction.
\end{abstract}

Keywords: perception, service, and satisfaction

Abstrak: Tujuan dilakukannya penelitian ini adalah untuk mengetahui: persepsi tentang kualitas pendidikan; pelayanan pendidikan; kepuasan orang tua siswa; hubungan persepsi kualitas pendidikan dengan kepuasan orang tua siswa; hubungan pelayanan pendidikan dengan kepuasan orang tua siswa; hubungan persepsi kualitas pendidikan dengan pelayanan pendidikan; dan hubungan persepsi kualitas dan pelayanan pendidikan dengan kepuasan orang tua siswa. Penelitian ini menggunakan pendekatan kuantitatif dengan rancangan penelitian deskriptif korelasional. Instrumen yang digunakan dalam penelitian ini berupa angket dengan responden orang tua siswa SMK Negeri di Kota Mojokerto. Teknik analisis data yang digunakan adalah teknik analisis deskriptif (mean) dan teknik analisis regresi ganda. Berdasarkan hasil penelitian dapat disimpulkan bahwa: tingkat persepsi kualitas pendidikan masuk dalam kategori sedang; tingkat pelayanan pendidikan masuk dalam kategori tinggi; tingkat kepuasan orang tua siswa masuk dalam kategori sedang; terdapat hubungan yang signifikan antara persepsi kualitas pendidikan dengan kepuasan orang tua siswa; terdapat hubungan yang signifikan antara pelayanan pendidikan dengan kepuasan orang tua; terdapat hubungan yang signifikan antara persepsi tentang kualitas pendidikan dengan pelayanan pendidikan; dan terdapat hubungan yang signifikan antara persepsi kualitas pendidikan dan pelayanan pendidikan dengan kepuasan orang tua siswa.

Kata kunci: persepsi, pelayanan, dan kepuasan 
Seiring berjalannya waktu kebutuhan individu terhadap sesuatu akan berubah-ubah. Tentunya kebutuhan tersebut menyesuaikan terhadap kemajuan zaman yang terjadi begitu cepat. Semakin lama standar kebutuhan individu terhadap sesuatu pasti akan lebih tinggi. Pemberi jasa layanan harus bisa menyediakan kualitas jasa layanannya seperti yang diharapkan pelanggan jasa. Hal tersebut juga berpengaruh pada jasa layanan lembaga pendidikan. Semakin majunya IPTEK akan berpengaruh dengan semakin maju pula teknologi tentang pendidikan. Kepuasan pelanggan adalah salah satu faktor yang penting bagi lembaga pendidikan. Kepuasan pelanggan adalah sebuah tolak ukur suatu lembaga terutama lembaga pendidikan apakah bisa dianggap sudah berhasil atau belum. Lembaga pendidikan yaitu sekolah dapat dikatakan berhasil ketika pelanggan bisa merasa puas dengan layanan yang diberikan oleh lembaga tersebut. Ketika pelanggan jasa pendidikan merasa tidak puas, bisa dikatakan lembaga tersebut telah gagal untuk memenuhi permintaan pelanggan. Rahma \& Hartoyo (2010:2) berpendapat bahwa siswa dan orang tua siswa disebut sebagai pengguna jasa pendidikan atau pelanggan.

Sekolah sebagai salah satu lembaga pendidikan selalu berusaha memberikan pelayanan terbaik kepada pelanggan. Sekolah selalu berusaha terus meningkatkan kualitas dari layanan jasa yang diberikan untuk pelanggan guna memenuhi kebutuhan pelanggan. Ketika kebutuhan pelanggan jasa terpenuhi maka orang tua siswa sebagai pelanggan tentunya akan merasa puas. Apabila pelanggan jasa merasa puas dengan layanan jasa yang diberikan sekolah, maka kepercayaan dan loyalitas yang dimiliki orang tua siswa sebagai pelanggan kepada sekolah akan semakin baik. Menurut pendapat Nasution (2004:44) perasaan puas atau tidak puas pelanggan merupakan respon dari pelanggan dengan membandingkan layanan yang diterima dengan layanan yang diharapkan oleh pelanggan. Pelanggan akan merasa tidak puas apabila hasilnya tidak sesuai harapan. Ketidakpuasan pelanggan pada layanan yang diberi sekolah merupakan salah satu faktor alasan penyebab sekolah semakin lama pelanggannya akan menurun dengan ditandai jumlah siswa semakin menurun, tentunya hal tersebut pasti dapat merugikan pihak sekolah. Ketika layanan jasa yang diperoleh pelanggan sesuai dengan apa yang diharapkan, mutu layanan dapat dipersepsikan sudah memuaskan.

Persepsi merupakan proses dari pengorganisasian, penerjemahan dari stimulus yang direkam oleh indera manusia melalui pengalaman yang bertujuan memberi arti bagi lingkungan mereka. Menurut pendapat Sugihartono (2007:7) persepsi merupakan tindakan manusia yang dimulai dengan proses penginderaan. Penginderaan merupakan proses masuk stimulus dalam alat panca indera manusia. Setelah stimulus terekam dalam panca indera manusia, otak akan menerjemahkan stimulus yang diterima. Kemampuan otak untuk mengartikan hasil stimulus disebut dengan persepsi.

Kualitas (mutu) suatu produk dapat berasal dari bahan pengerjaan atau teknologi yang digunakan. Menurut Wijaya (2011:11) kualitas merupakan hal dari sesuatu yang dipilih oleh pelanggan. Artinya kualitas berdasarkan pada dari pengalaman terhadap produk suatu penyedia jasa yang dapat berpedoman berdasarkan standar tertentu. Adapun menurut Minarti (2012:329) mutu pendidikan dapat dinilai dari masukan, proses luaran, dan dampaknya. Persepsi tentang kualitas dari pendidikan merupakan kemampuan memberikan penilaian terhadap keunggulan dari suatu layanan jasa pendidikan yang dapat menghasilkan keunggulan akademik dan non akademik pada siswa dengan mengacu daripada masukan, proses dari luaran, dan dampak yang disebabkan. Orang tua siswa yang menjadi pelanggan tentu berharap kualitas sekolah yang dituju dapat memberi ilmu pengetahuan bagi putra putri mereka.

Berdasarkan hasil penelitian di SMK Negeri Kota Mojokerto diketahui persepsi orang tua siswa tentang kualitas pendidikan masuk dalam kategori sedang, pelayanan pendidikan masuk dalam kategori tinggi, dan kepuasan orang tua siswa masuk dalam kategori sedang. Sekolah mempunyai tugas penting untuk memberikan layanan jasa pendidikan yang dikatakan berkualitas pada siswa dan orang tua siswa. Orang tua siswa yang menjadi salah satu pelanggan jasa pendidikan pasti mengharapkan fasilitas pelayanan sekolah yang bermutu bagi anak mereka, sehingga puta putri mereka dapat memanfaatkan fasilitas tersebut untuk meningkatkan kemampuannya.

Pelayanan pendidikan adalah kegiatan guna memenuhi segala keinginan yang dibutuhkan oleh pelanggan. Pelayanan yang berkualitas akan membuat pelanggan pendidikan merasa puas karena merasa kebutuhannya telah dipenuhi dengan baik bahkan lebih dari harapan yang diharapkan pelanggan. 
Menurut Prihastono (2012) pelayanan adalah kepuasan yang pelanggan peroleh dari perilaku yang dilakukan individu. Indikator pengukuran kualitas pelayanan, yaitu: 1) berwujud (tangiables); 2) keandalan (reliability), kemampuan penyedia layanan; 3) daya tanggap (responsibility); 4) jaminan (assurance); 5) empati (emphaty), adanya rasa peduli (Kotler, 2007:231).

Peraturan Pemerintah Nomor 32 Tahun 2013 tentang Standar Nasional Pendidikan (SNP). Pada Pasal 1 menjelaskan bahwa SNP merupakan kriteria minimal untuk sistem pendidikan di seluruh wilayah hukum Negara Kesatuan Republik Indonesia. Pedoman tentang mutu pada lembaga pendidikan juga bisa dilihat pada Undang-Undang Nomor 20 Tahun 2003 tentang Sistem Pendidikan Nasional dan Peraturan Pemerintah Nomor 19 Tahun 2005 tentang Standar Nasional Pendidikan bahwa penjaminan kualitas atau mutu adalah wajib baik dari internal maupun dari eksternal.

Sekolah Menengah Kejuruan di Kota Mojokerto merupakan lembaga pendidikan yang menawarkan layanan jasa dalam bidang pendidikan. Sekolah seharusnya mempunyai kualitas pendidikan dan layanan jasa pendidikan yang baik. Jika lembaga pendidikan mempunyai kualitas yang sangat baik, maka hal tersebut dapat menghasilkan output yang baik pula. Generasi yang mempunyai kualitas yang baik sangat dibutuhkan dalam membangun negeri agar semakin lebih baik lagi.

\section{METODE}

Penelitian ini menggunakan pendekatan kuantitatif dengan rancangan penelitian deskriptif korelasional. Sugiyono $(2013: 14)$ mengatakan bahwa metode penelitian kuantitatif sebagai metode penelitian yang berlandaskan daripada filsafat positivisme yang dimanfaatkan untuk meneliti populasi atau sampel dengan ciri tertentu dan menggunakan teknik pengambilan sampel yang biasanya dilakukan secara random. Pengumpulan data menggunakan instrumen atau angket. Analisis data bersifat kuantitatif atau statistik yang bertujuan untuk menguji hipotesis yang telah ditetapkan. Adapun kerangka pemikiran yang dibuat oleh penelitian dapat dilihat pada Gambar 1 sebagai berikut:

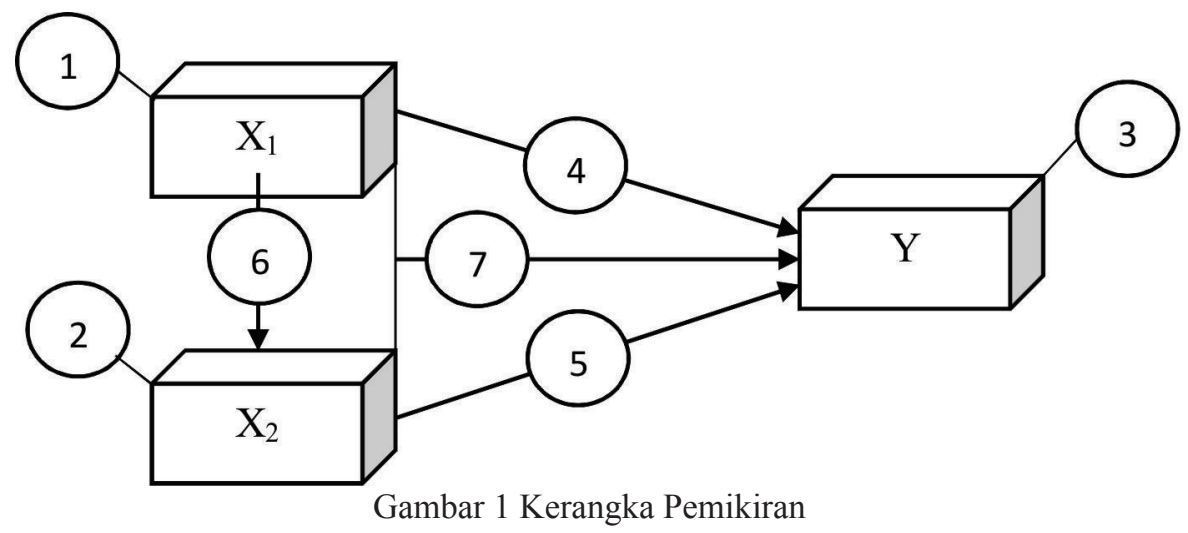

Keterangan:

$\mathrm{X} 1$ = Variabel $\mathrm{X} 1$ persepsi kualitas pendidikan;

$\mathrm{X} 2$ = Variabel X2 pelayanan pendidikan;

$\mathrm{Y}=$ Variabel $\mathrm{Y}$ kepuasan orang tua siswa.

Penelitian ini menggunakan sampel sejumlah 345 orang tua siswa dari populasi sejumlah 2.508 orang tua siswa dengan lokasi penelitian SMK Negeri di Kota Mojokerto. Instrumen yang digunakan dalam penelitian ini berupa angket. Teknik analisis data yang digunakan adalah teknik analisis deskriptif (mean) dan teknik analisis regresi ganda dengan menggunakan program SPSS (Statistical Product and Service Solution) for Windows versi 16.0. 


\section{HASIL}

\section{Deskriptif Variabel Persepsi Kualitas Pendidikan (X1)}

Berdasarkan hasil analisis didapatkan deskripsi data variabel X1 yang dapat dilihat sebagai berikut. Tabel 1 Hasil Analisis Deskriptif Variabel X1

\begin{tabular}{|c|c|c|c|c|}
\hline No. & Interval & Kategori & Frekuensi & Persentase \\
\hline 1 & $168-208$ & Rendah & 66 & 19,13 \\
\hline 2 & 209-249 & Sedang & 198 & 57,40 \\
\hline 3 & $\geq 250$ & Tinggi & 81 & 23,47 \\
\hline \multicolumn{3}{|c|}{ TOTAL } & 345 & 100 \\
\hline
\end{tabular}

Dilihat dari Tabel 1 pada interval 168-208 didapat 66 responden (19,13\%) masuk kategori rendah. Interval 209-249 didapat 198 responden (57,40\%) masuk kategori sedang. Sedangkan untuk interval $\geq 250$ didapat 81 responden (23,47\%) masuk kategori tinggi. Mean (rata-rata) pada variabel X1 diperoleh hasil 232,45 dan berada di interval 209-249 sehingga masuk kategori sedang.

Berikut adalah hasil analisis deskriptif variabel X1 pada masing-masing sekolah yang dapat dilihat pada Tabel 2

Tabel 2 Hasil Analisis Deskriptif Variabel X1 Setiap Sekola

\begin{tabular}{cccc}
\hline No. & Sekolah & Kategori & Rata-rata \\
\hline 1. & SMK Negeri 1 Kota Mojokerto & Sedang & 231,04 \\
2. & SMK Negeri 2 Kota Mojokerto & Sedang & 234,42 \\
\hline
\end{tabular}

Berdasarkan Tabel 2 diketahui SMK Negeri 1 Kota Mojokerto memperoleh hasil rata-rata 231,04 masuk kategori sedang. SMK Negeri 2 Kota Mojokerto memperoleh hasil rata-rata 234,42 masuk kategori sedang. Dapat disimpulkan bahwa rata-rata yang diperoleh SMK Negeri 2 Kota Mojokerto lebih tinggi yaitu sebesar 234,42.

\section{Deskriptif Variabel Pelayanan Pendidikan (X2)}

Berdasarkan hasil analisis didapatkan deskripsi data variabel X2 yang dapat dilihat sebagai berikut. Tabel 3 Hasil Analisis Deskriptif Variabel X2

\begin{tabular}{|c|c|c|c|c|}
\hline No. & Interval & Kategori & Frekuensi & Persentase \\
\hline 1 & $61-101$ & Rendah & 8 & 2,32 \\
\hline 2 & $102-142$ & Sedang & 143 & 41,45 \\
\hline 3 & $\geq 143$ & Tinggi & 194 & 56,23 \\
\hline \multicolumn{3}{|c|}{ TOTAL } & 345 & 100 \\
\hline
\end{tabular}

Dilihat dari Tabel 3 pada interval 61-101 didapat 8 responden (2,32\%) masuk kategori rendah. Interval 102-142 didapat 143 responden (41,45\%) masuk kategori sedang. Sedangkan untuk interval $\geq 143$ didapat 194 responden $(56,23 \%)$ masuk kategori tinggi. Mean (rata-rata) pada variabel X2 diperoleh hasil 146,23 dan berada pada interval $\geq 143$ sehingga masuk kategori tinggi.

Berikut adalah hasil analisis deskriptif variabel X2 pada masing-masing sekolah yang dapat dilihat pada Tabel 4.

Tabel 4 Hasil Analisis Deskriptif Variabel X2 Setiap Sekolah

\begin{tabular}{cccc}
\hline No. & Sekolah & Kategori & Rata-rata \\
\hline 1. & SMK Negeri 1 Kota Mojokerto & Tinggi & 144,22 \\
2. & SMK Negeri 2 Kota Mojokerto & Tinggi & 149,04 \\
\hline
\end{tabular}


Berdasarkan Tabel 4 diketahui SMK Negeri 1 Kota Mojokerto memperoleh hasil rata-rata 144,22 masuk kategori tinggi. SMK Negeri 2 Kota Mojokerto memperoleh hasil rata-rata 149,04 masuk kategori tinggi. Dapat disimpulkan bahwa rata-rata yang diperoleh SMK Negeri 2 Kota Mojokerto lebih tinggi yaitu sebesar 149,04.

\section{Deskriptif Variabel Kepuasan Orang Tua Siswa (Y)}

Berdasarkan hasil analisis didapatkan deskripsi data variabel $\mathrm{Y}$ yang dapat dilihat sebagai berikut. Tabel 5 Hasil Analisis Deskriptif Variabel Y

\begin{tabular}{|c|c|c|c|c|}
\hline No. & Interval & Kategori & Frekuensi & Persentase \\
\hline 1 & $54-68$ & Rendah & 54 & 15,65 \\
\hline 2 & $69-83$ & Sedang & 139 & 40,30 \\
\hline 3 & $\geq 84$ & Tinggi & 152 & 44,05 \\
\hline
\end{tabular}

Dilihat pada Tabel 5 pada interval 54-68 didapat 54 responden $(15,65)$ masuk kategori rendah. Interval 69-83 didapat 139 responden $(40,30 \%)$ masuk kategori sedang. Sedangkan untuk interval $\geq 84$ didapat 152 responden $(44,05 \%)$ masuk kategori tinggi. Mean (rata-rata) pada variabel Y diperoleh hasil 81,79 dan berada pada interval 69-83 sehingga masuk kategori sedang.

Berikut adalah hasil analisis deskriptif variabel Y pada masing-masing sekolah yang dapat dilihat pada Tabel 6.

Tabel 6 Hasil Analisis Deskriptif Variabel Y Setiap Sekolah

\begin{tabular}{cccc}
\hline No. & Sekolah & Kategori & Rata-rata \\
\hline 1. & SMK Negeri 1 Kota Mojokerto & Sedang & 81,04 \\
2. & SMK Negeri 2 Kota Mojokerto & Sedang & 82,84 \\
\hline
\end{tabular}

Berdasarkan Tabel 6 diketahui SMK Negeri 1 Kota Mojokerto memperoleh hasil rata-rata 81,04 masuk kategori sedang. SMK Negeri 2 Kota Mojokerto memperoleh hasil rata-rata 82,84 masuk kategori sedang. Dapat disimpulkan bahwa rata-rata yang diperoleh SMK Negeri 2 Kota Mojokerto lebih tinggi yaitu sebesar 82,84 .

Hasil analisis deskriptif variabel X1, X2, dan Y dirangkum menjadi satu sehingga menghasilkan data seperti pada Tabel 7.

Tabel 7 Hasil Analisis Deskriptif Variabel X1, X2, dan Y

\begin{tabular}{cccccc}
\hline \multirow{2}{*}{ No. } & \multirow{2}{*}{ Sekolah } & \multicolumn{3}{c}{ Rata-Rata } & \multirow{2}{*}{$\begin{array}{c}\text { Rata-rata } \\
\text { Akhir }\end{array}$} \\
\cline { 3 - 5 } & & $\mathrm{X} 1$ & $\mathrm{X} 2$ & $\mathrm{Y}$ & 152,10 \\
\hline 1. & SMK Negeri 1 Kota Mojokerto & 231,04 & 144,22 & 81,04 & 150 \\
2. & SMK Negeri 2 Kota Mojokerto & 234,42 & 149,04 & 82,84 & 155,43 \\
\hline
\end{tabular}

Berdasarkan Tabel 7 diketahui hasil analisis deskriptif variabel X1, X2, dan Y SMK Negeri 1 Kota Mojokerto memperoleh hasil rata-rata akhir 152,10. Sedangkan SMK Negeri 2 Kota Mojokerto memperoleh hasil rata-rata akhir 155,43. Dapat disimpulkan bahwa rata-rata akhir yang diperoleh SMK Negeri 2 Kota Mojokerto lebih tinggi yaitu sebesar 155,43.

\section{Analisis Deskriptif Identitas Responden}

Responden pada penelitian ini adalah orang tua siswa SMK Negeri di Kota Mojokerto. Karakteristik responden dibagi menjadi empat kategori berdasarkan: 1) usia; 2) jenis kelamin; 3) pendidikan; dan 4) pekerjaan. Hasil analisis deskriptif identitas responden dapat dilihat pada Tabel 8, 9, 10, dan 11. 
Tabel 8 Karakteristik Usia

\begin{tabular}{cccccc}
\hline & & Frequency & Percent & Valid Percent & Cumulative Percent \\
\hline Valid & $<$ 30 Tahun & 23 & 6.7 & 6.7 & 6.7 \\
& 31-40 Tahun & 107 & 31.0 & 31.0 & 37.7 \\
& $>40$ Tahun & 215 & 62.3 & 62.3 & 100.0 \\
\hline Total & 345 & 100.0 & 100.0 & \\
\hline
\end{tabular}

Tabel 9 Karakteristik Jenis Kelamin

\begin{tabular}{cccccc}
\hline & & Frequency & Percent & Valid Percent & Cumulative Percent \\
\hline \multirow{2}{*}{ Valid } & Laki-laki & 170 & 49.3 & 49.3 & 49.3 \\
& Perempuan & 175 & 50.7 & 50.7 & 100.0 \\
\hline \multicolumn{2}{c}{ Total } & 345 & 100.0 & 100.0 & \\
\hline
\end{tabular}

Tabel 10 Karakteristik Pendidikan

\begin{tabular}{cccccc}
\hline & & Frequency & Percent & Valid Percent & Cumulative Percent \\
\hline Valid & SD & 74 & 21.4 & 21.4 & 21.4 \\
& SMP & 61 & 17.7 & 17.7 & 39.1 \\
& SMA & 159 & 46.1 & 46.1 & 85.2 \\
S1 & 48 & 13.9 & 13.9 & 99.1 \\
& S2 & 3 & .9 & .9 & 100.0 \\
\hline Total & 345 & 100.0 & 100.0 & \\
\hline
\end{tabular}

Tabel 11 Karakteristik Pekerjaan

\begin{tabular}{cccccc}
\hline & & Frequency & Percent & Valid Percent & Cumulative Percent \\
\hline \multirow{4}{*}{ Valid } & Swasta & 195 & 56.5 & 56.5 & 56.5 \\
& Wiraswasta & 132 & 38.3 & 38.3 & 94.8 \\
& PNS & 18 & 5.2 & 5.2 & 100.0 \\
\hline & Total & 345 & 100.0 & 100.0 & \\
\hline
\end{tabular}

\section{PEMBAHASAN}

\section{Persepsi Kualitas Pendidikan}

Persepsi merupakan suatu proses pengorganisasian, penginterpretasian dari stimulus yang direkam oleh indera individu melalui pengalaman dengan mempunyai tujuan untuk memberi arti bagi lingkungan mereka. Persepsi konsumen sangat penting guna dipelajari oleh penyedia jasa, karena perilaku pelanggan jasa didasarkan pada persepsi mereka. Berdasarkan hasil penelitian mean (rata-rata) pada variabel X1 diperoleh hasil 232,45 berada pada interval 209-249 sehingga masuk kategori sedang.

Hasil penelitian ini sesuai dengan hasil temuan penelitian yang dilakukan oleh Setiawan (2015) bahwa tingkat persepsi peserta didik tentang media jejaring sosial dalam pemanfaatannya untuk belajar di SLTA Kota Malang berada dalam kategori sedang. Sumarsono (2012) juga melakukan penelitian dengan hasil yang sama yaitu mahasiswa memandang kualitas produk/fisik laboratorium AP FIP UM sudah cukup baik. Penelitian yang dilakukan oleh Sari, Supriyanto, dan Zulkarnain (2017) juga mendapatkan hasil yang sama bahwa persepsi orang tua peserta didik tentang mutu pendidikan di SDN Purwodadi 03 Kecamatan Purwodadi Kabupaten Pasuruan berada pada kategori tinggi.

Dapat disimpulkan bahwa persepsi kualitas pendidikan SMK Negeri di Kota Mojokerto masuk dalam kategori sedang. Berdasarkan hasil tersebut, perlu adanya peningkatan kualitas pendidikan. Kualitas pendidikan yang baik akan memengaruhi persepsi orang tua siswa. Jika kualitas pendidikan 
dalam kategori yang tinggi, maka persepsi orang tua siswa tentang kualitas pendidikan juga akan semakin tinggi.

\section{Pelayanan Pendidikan}

Pelayanan pendidikan merupakan suatu kegiatan guna untuk memenuhi segala keinginan yang dibutuhkan oleh pelanggan. Pelayanan yang berkualitas akan membuat pelanggan jasa pendidikan merasa puas karena merasa kebutuhannya telah dipenuhi dengan baik bahkan lebih dari harapan yang diinginkan oleh pelanggan. Berdasarkan hasil penelitian mean (rata-rata) pada variabel X2 diperoleh hasil 146,23 berada pada interval $\geq 143$ sehingga masuk kategori tinggi.

Hasil penelitian ini sesuai dengan hasil temuan penelitian yang dilakukan oleh Sari dan Wiyono (2013) bahwa kondisi kualitas pelayanan yang terdiri atas bukti fisik, keandalan, daya tanggap, jaminan, dan empati yang diberikan kepada peserta didik di SMK Negeri se-Kota Malang secara umum berada dalam kategori baik. Liana, Benty, dan Supriyanto (2016) juga melakukan penelitian dengan hasil yang sama yaitu tingkat kepuasan orang tua peserta didik terhadap layanan pendidikan ada pada kategori sangat tinggi.

Dapat disimpulkan bahwa pelayanan pendidikan SMK Negeri di Kota Mojokerto masuk kategori tinggi. Berdasarkan hasil tersebut, kualitas pelayanan perlu dipertahankan atau bisa ditingkatkan lagi. Pelayanan pendidikan yang berkualitas baik akan memengaruhi minat pelanggan atau orang tua siswa untuk menggunakan jasa layanan pendidikan yang ditawarkan oleh sekolah. Sebaliknya jika kualitas layanan jasa pendidikan dalam kategori yang rendah, maka minat orang tua siswa untuk menggunakan jasa pendidikan juga akan semakin rendah.

\section{Kepuasan Orang Tua Siswa}

Kepuasan pada dasarnya adalah suatu perasaan seseorang setelah mendapatkan pelayanan/perlakuan yang baik dan melebihi dari perkiraan sebelumnya. Jika pelanggan merasa puas, maka loyalitas terhadap lembaga pendidikan atau sekolah akan semakin tinggi dan citra lembaga pendidikan tersebut akan semakin lebih baik di mata masyarakat. Berdasarkan hasil penelitian mean (rata-rata) pada variabel Y diperoleh hasil 81,79 berada pada interval 69-83 sehingga masuk kategori sedang.

Penelitian ini mempunyai hasil yang sama dengan penelitian yang dilakukan oleh Prastiawan, Mustiningsih, dan Wiyono (2016) bahwa tingkat kepuasan peserta didik terhadap fasilitas sekolah di SMA Negeri Kota Malang berada dalam kategori sedang. Sari dan Wiyono (2013) juga melakukan penelitian dengan hasil yang sama yaitu tingkat kepuasan peserta didik dan orang tua peserta didik akan pelayanan pendidikan yang diberikan oleh SMK Negeri se-Kota Malang secara umum berada dalam kategori sedang atau cukup puas.

Dapat disimpulkan bahwa kepuasan orang tua siswa SMK Negeri di Kota Mojokerto masuk dalam kategori sedang. Berdasarkan hasil tersebut, perlu adanya peningkatan kualitas faktor-faktor yang memengaruhi kepuasan orang tua siswa yaitu peningkatan kualitas dan pelayanan pendidikan. Semakin baik kualitas dan pelayanan pendidikan maka semakin puas yang dirasakan orang tua siswa. Sebaliknya jika semakin rendah kualitas dan pelayanan pendidikan maka semakin rendah pula kepuasan orang tua siswa.

\section{Hubungan Persepsi Kualitas Pendidikan dengan Kepuasan Orang Tua Siswa}

Berdasarkan hasil uji korelasi product moment pearson diperoleh rhitung sebesar 0,705 dan nilai signifikansi 0.000 . Jika skor rhitung $>$ rtabel $(0,705>0,113)$ dan nilai signifikansinya lebih kecil dari $0,05(0,000<0,05)$, dapat disimpulkan ada hubungan yang signifikasn antara persepsi tentang kualitas pendidikan dengan kepuasan orang tua siswa. Hasil penelitian tersebut sesuai dengan penelitian yang dilakukan oleh Prastiawan, Mustiningsih, dan Wiyono (2016) bahwa terdapat hubungan yang signifikan antara mutu fasilitas sekolah dengan kepuasan peserta didik di SMA Negeri Kota Malang. Penelitian yang dilakukan oleh Sari, Supriyanto, dan Zulkarnain (2017) juga memperoleh hasil yang sama bahwa terdapat keterkaitan yang signifikan antara persepsi orang tua peserta didik tentang mutu pendidikan dengan tingkat kepercayaannya terhadap SDN Purwodadi 03.

Ketika kualitas pendidikan yang dimiliki sekolah dalam kategori baik, maka hal tersebut dapat mempengaruhi persepsi orang tua siswa dan berdampak pada kepuasan orang tua siswa. Kepuasan orang tua siswa terhadap lembaga pendidikan dapat diukur salah satunya dari kualitas produk yang diberikan sekolah kepada pelanggan. Jika sekolah ingin pelanggannya merasa puas dengan jasa yang mereka tawarkan maka sekolah harus mampu menjamin kualitas pendidikan yang dimiliki. Karena semakin baik kualitas pendidikan yang dimiliki sekolah maka orang tua siswa akan merasa lebih puas dengan jasa yang diberikan oleh sekolah. 


\section{Hubungan Pelayanan Pendidikan dengan Kepuasan Orang Tua Siswa}

Berdasarkan hasil uji korelasi product moment pearson diperoleh rhitung sebesar 0,796 dan nilai signifikansi 0.000 . Jika skor rhitung $>$ rtabel $(0,796>0,113)$ dan nilai signifikansinya lebih kecil dari 0,05 $(0,000<0,05)$, dapat disimpulkan ada hubungan yang signifikan antara pelayanan pendidikan dengan kepuasan orang tua siswa. Pramono, Sarma, dan Munandar (2017) juga memperoleh hasil yang sama bahwa kualitas pelayanan (e-Service Quality) berpengaruh langsung secara positif dan signifikan terhadap kepuasan siswa maupun orang tua. Rintar (2011) juga melakukan penelitian dengan hasil yang sama bahwa terdapat hubungan antara kualitas jasa dan kepuasan konsumen pada lembaga pendidikan kejuruan.

Pelayanan pendidikan adalah sebuah kegiatan untuk memenuhi semua keinginan yang dibutuhkan pelanggan. Pelayanan yang berkualitas baik akan membuat pelanggan pendidikan merasa puas karena merasa kebutuhannya telah dipenuhi dengan baik bahkan lebih dari harapan yang diinginkan oleh pelanggan. Sekolah sebagai salah satu lembaga pendidikan harus menjaga pelayanan agar tetap prima supaya pelanggan bisa selalu merasa puas dengan layanan yang diberikan. Karena jika semakin baik kualitas layanan jasa pendidikan yang diberikan sekolah kepada orang tua siswa, maka mereka akan merasa lebih puas dengan pelayanan yang diberikan oleh sekolah.

\section{Hubungan Persepsi Kualitas dan Pelayanan Pendidikan}

Berdasarkan hasil uji korelasi product moment pearson diperoleh rhitung sebesar 0,799 dan nilai signifikansi 0.000 . Jika skor rhitung $>$ rtabel $(0,799>0,106)$ dan nilai signifikansinya lebih kecil dari 0,05 $(0,000<0,05)$, dapat disimpulkan ada hubungan yang signifikan antara persepsi tentang kualitas dan pelayanan pendidikan. Hasil penelitian tersebut sesuai dengan hasil penelitian yang dilakukan oleh Murty (2014) bahwa kualitas layanan pendidikan berpengaruh terhadap persepsi siswa SMA Santo Ignasius. Hasil penelitian tersebut sesuai dengan hasil penelitian yang dilakukan oleh Martin (2016) menyimpulkan bahwa kepuasan pelanggan terkait dengan persepsi kualitas pelayanan dan harapan pelanggan kualitas layanan melebihi persepsi mereka meskipun mereka umumnya puas.

Penelitian yang dilakukan oleh Ragavan \& Mageh (2013) dimana dari hasil penelitian mereka menyimpulkan hasil yang sama yaitu persepsi pelangan terhadap kualitas layanan sangat mempengaruhi kepuasan pelanggan. Jika layanan jasa pendidikan yang diterima sesuai dengan harapan pelanggan, maka mutu pelayanan dapat dikatakan menjadi memuaskan. Sehingga dapat disimpulkan bahwa persepsi tentang kualitas dan pelayanan pendidikan mempunyai hubungan yang signifikan.

\section{Hubungan Persepsi Tentang Kualitas dan Pelayanan Pendidikan Dengan Kepuasan Orang Tua Siswa SMK Negeri di Kota Mojokerto}

Berdasarkan hasil uji F diketahui hasil nilai Fhitung 312,696 dan diperoleh signifikansi 0,000. Jika nilai Fhitung $>$ Ftabel $(312,696>3,022)$ dan signifikansi $<0,05(0,000<0,05)$ maka H0 ditolak dan H1 diterima. Dapat disimpulkan H0 ditolak atau variabel X1 dan X2 mempunyai pengaruh yang signifikan secara bersama-sama terhadap variabel Y. Sedangkan berdasarkan analisis koefisien determinasi (R2) diperoleh nilai $\mathrm{R}$ 0,804. Hasil tersebut menunjukkan hubungan variabel X1 dan X2 dengan Y sebesar $80,4 \%$. Sedangkan diperoleh nilai $R$-Square sebesar 0,646. Dapat disimpulkan variabel X1 dan X2 berpengaruh sebesar $64,6 \%$ terhadap variabel $\mathrm{Y}$, sedangkan 35,4\% dipengaruhi variabel lain yang tidak diteliti.

Hasil penelitian yang dilakukan Sadiq, Rehman, \& Anjum (2013) juga mengungkapkan bahwa persepsi pelangan terhadap kualitas layanan sangat mempengaruhi kepuasan pelanggan. Segoro (2011) juga membuktikan dengan penelitian yang dilakukannya bahwa persepsi kualitas pelayanan berpengaruh signifikan terhadap kepuasan pelanggan. Sehingga dapat disimpulkan persepsi tentang kualitas dan pelayanan pendidikan mempunyai pengaruh yang signifikan secara bersama-sama terhadap kepuasan orang tua siswa. Hasil tersebut menunjukkan bahwa persepsi tentang kualitas dan pelayangan berpengaruh sebesar $80,4 \%$ dengan kepuasan orang tua siswa. Sedangkan persepsi tentang kualitas dan pelayanan pendidikan berpengaruh sebesar $64,6 \%$ terhadap kepuasan orang tua siswa SMK Negeri di Kota Mojokerto, 35,4\% dipengaruhi variabel lain yang tidak diteliti. 


\section{KESIMPULAN DAN SARAN}

\section{Kesimpulan}

Berdasarkan hasil penelitian dapat disimpulkan bahwa: 1) persepsi tentang kualitas pendidikan masuk kategori sedang; 2) pelayanan pendidikan masuk kategori tinggi; 3) kepuasan orang tua siswa masuk kategori sedang; 4) terdapat hubungan yang signifikan antara persepsi tentang kualitas pendidikan dengan kepuasan orang tua siswa; 5) terdapat hubungan yang signifikan antara pelayanan pendidikan dengan kepuasan orang tua siswa; 6 ) terdapat hubungan yang signifikan antara persepsi tentang kualitas dan pelayanan pendidikan; dan 7) terdapat hubungan yang signifikan antara persepsi kualitas dan pelayanan pendidikan dengan kepuasan orang tua siswa SMK Negeri di Kota Mojokerto

\section{Saran}

Saran yang dikemukakan dalam penelitian ini yaitu: 1) Kepala Dinas Pendidikan dan Kebudayaan Provinsi Jawa Timur, berdasarkan hasil penelitian diperoleh persepsi orang tua siswa tentang kualitas pendidikan masuk kategori sedang. Kondisi ini diharapkan dapat memberikan masukan terhadap kepala dinas pendidikan dan kebudayaan Provinsi Jawa Timur khususnya dalam pendidikan sekolah menengah kejuruan supaya lebih meningkatkan kualitas pendidikan. Jika kualitas pendidikan semakin tinggi, maka akan semakin tinggi pula kepuasan orang tua siswa; 2) Kepala SMK Negeri di Kota Mojokerto, sebaiknya meningkatkan kualitas pendidikan karena berdasarkan hasil penelitian kualitas pendidikan masuk dalam kategori sedang. Semakin baik kualitas atau mutu pendidikan sekolah, maka akan berdampak semakin tinggi pula kepuasan yang dirasakan orang tua siswa; 3) Ketua Jurusan Administrasi Pendidikan, hasil penelitian bisa digunakan untuk bahan perkuliahan dan referensi untuk penelitian mahasiswa administrasi pendidikan guna menambah ilmu pengetahuan yang terkait dengan hubungan persepsi kualitas pendidikan dan pelayanan pendidikan dengan kepuasan orang tua siswa; dan 4) Peneliti Lain, hasil penelitian ini dapat dijadikan sebagai sumber referensi untuk penelitian selanjutnya dengan konteks yang sama. Peneliti lain yang akan melakukan penelitian terkait dengan kepuasan orang tua siswa diharapkan peneliti menggunakan variabel yang lain dan selaras dengan kepuasan orang tua.

\section{DAFTAR RUJUKAN}

Kotler, P. 2007. Manajemen Pemasaran : Analisis, perencanaan, Implementasi, dan Pengendalian. Jakarta : Salemba Empat.

Liana, N. A, Benty, D. D. N, \& Supriyanto, A. 2016. Analisis Faktor Yang Mempengaruhi Kepuasan Orang Tua Peserta Didik Terhadap Layanan Pendidikan. Jurnal Manajemen Pendidikan, 25(1), 39- 46.

Martin, M. J. 2016. Customers' Determination Of Service Quality And Satisfaction In A Return/Repair Process: A Quantitative Study. International Academy of Marketing Studies Journal, 20(1), 36- 52.

Minarti, S. 2012. Manajemen Sekolah: Mengelola Lembaga Pendidikan Secara Mandiri. Yogyakarta: Ar-Ruzz Media.

Murty, Y. H. 2014. Pengaruh Kualitas Layanan Pendidikan Terhadap Persepsi dan Kepercayaan Siswa Serta Dampaknya Terhadap Kepuasan Siswa di SMA Santo Ignasius Singkawang. Skripsi tidak diterbitkan. Jakarta: Pascasarjana Universitas Terbuka.

Nasution, M. N. 2004. Manajemen Mutu Terpadu. Jakarta: Ghalia Indonesia.

Peraturan Pemerintah Nomor 32 Tahun 2013 Tentang Standar Nasional Pendidikan. 2013. Jakarta: Sinar Grafika.

Peraturan Pemerintah Nomor 19 Tahun 2005 tentang Standar Nasional Pendidikan, (Online), (http://www. depdiknas.go.id, diakses 2 Mei 2018).

Pramono, S., Sarma, M., \& Munandar, J. M. 2017. Kepuasan dan Loyalitas Siswa dan Orang Tua Terhadap Penggunaan Layanan Online Berdasarkan Kualitas Pelayanan dan Kualitas Tampilan Laman (Web) di SMK Negeri 1 Kota Bogor. Jurnal Manajemen dan Organisasi, 8(1), 43- 59. Dari http://journal.ipb.ac.id/index. php/jmo/article/view/18600.

Prastiawan, A., Mustiningsih, \& Wiyono, B. B. 2016. Hubungan Mutu Fasilitas Sekolah dengan Kepuasan Peserta Didik di Sekolah Menengah Atas Negeri. Jurnal Manajemen Pendidikan, 25(2), 215- 223.

Prihastono, E. 2012. Pengukuran Kepuasan Konsumen pada Kualitas Pelayanan Customer Service berbasis WEB. Jurnal Ilmiah Dinamika Teknik. Dari download.portalgaruda.org. 
Rahma, A. \& Hartoyo. 2010. Pengaruh Karakteristik Orang Tua dan Sekolah Terhadap Tingkat Kepuasan Pelayanan Pendidikan Dasar. Jurnal Ilmu Keluarga \& Konsumen 3. Dari http://download.portalgaruda.org/

Article.php?article $=86088 \& v a l=239$.

Ragavan \& Mageh. 2013. A Study on Service Quality Perspectives and Customer Satisfaction in New Private Sector Banks. IOSR Journal of Business and Management (IOSR-JBM), 7(2), 26-33.

Rintar. 2011. Analisis Hubungan Kualitas Jasa Terhadap Kepuasan Konsumen Pada Lembaga Pendidikan Kejuruan. Jurnal Dinamika Manajemen, 2(1), 40-47. Dari https://journal.unnes.ac.id/artikel_nju/jdm/2486.

Sadiq, M., Rehman, S. U., \& Anjum, K. M. J. 2013. Customers' Perception of Service Quality in Banking and The Level Of Customers' Satisfaction: A Study of Maybank Berhad. Actual Problems of Economics, 11(149), 494- 504 .

Sari, R. P. \& Wiyono, B. B. (2013). Pengaruh Kualitas Pelayanan Sekolah Terhadap Kepuasan Peserta Didik dan Orang Tua Peserta Didik. Jurnal Manajemen Pendidikan, 24(2), 146- 156.

Sari, R. R., Supriyanto, A., \& Zulkarnain, W. 2017. Persepsi dan Ekspektasi Orang Tua Peserta Didik Tentang Mutu Pendidikan Berkaitan Dengan Kepercayaannya Terhadap SDN Purwodadi 03 Kecamatan Purwodadi Kabupaten Pasuruan. Skripsi tidak diterbitkan. Malang: FIP UM.

Segoro, W. 2011. Pengaruh Persepsi Kualitas Pelayanan, Faktor Penambat

Dan Kualitas Hubungan Relasional Terhadap Kepuasan Dan Loyalitas

Pelanggan: Suatu Penelitian Pada Penyedia Jasa Telepon Selular Di Jawa

Barat. Jurnal Telekomunikasi dan Komputer, 2(2), 181- 197.

Setiawan, A. C., Setyadin, B., \& Sumarsono, R. B. 2015. Persepsi dan Sikap Peserta Didik Tentang Media Jejaring Sosial Dalam Pemanfaatannya Untuk Belajar. Jurnal Manajemen Pendidikan, 24(5), 408- 415.

Sugihartono. 2007. Psikologi Pendidikan. Yogyakarta: UNY Press.

Sugiyono. 2013. Metode Penelitian Pendidikan (Pendekatan Kuantitatif, Kualitatif, dan R\&D). Bandung: Alfabeta.

Sumarsono, R. B. 2012. Faktor Yang Mempengaruhi Kepuasan Mahasiswa Terhadap Kualitas Layanan Laboratorium. Jurnal Manajemen Pendidikan, 23, 411- 417.

Undang-Undang Republik Indonesia Nomor 20 Tahun 2003 tentang Sistem Pendidikan Nasional. 2006. Bandung: Fokus Media.

Wijaya, T. 2011. Manajemen Kualitas Jasa. Jakarta: Permata Puri Media. 